\title{
Modeling and Control of a Multifunctional Three-Phase Converter for Bidirectional Power Flow in Plug-In Electric Vehicles
}

\author{
Reza Sabzehgar ${ }^{1, * \mathbb{D}}$, Yaser M. Roshan ${ }^{2}$ and Poria Fajri ${ }^{3}$ (i) \\ 1 Department of Electrical and Computer Engineering, San Diego State University, San Diego, CA 92128, USA \\ 2 School of Mechatronic Systems Engineering, Simon Fraser University, Surrey, BC V3T 0A3, Canada; \\ yaserm@sfu.ca \\ 3 Department of Electrical and Biomedical Engineering, University of Nevada Reno, Reno, NV 89557, USA; \\ pfajri@unr.edu \\ * Correspondence: rsabzehgar@sdsu.edu; Tel.: +1-619-594-7791
}

Received: 14 April 2020; Accepted: 17 May 2020; Published: 20 May 2020

\begin{abstract}
A nonlinear sliding-mode controller for a three-phase converter, utilized in plug-in electric vehicles (PEVs), is proposed in this paper. The proposed controller enables the utilized converter to perform multiple functions during different operating modes of the vehicle, i.e., grid-to-vehicle $(\mathrm{G} 2 \mathrm{~V})$ and vehicle-to-grid (V2G) modes. The bidirectional three-phase converter and the proposed controller operate as a power factor correction circuit, bridgeless boost converter, and rectifier during G2V mode (i.e., plug-in charging), and it operates as a conventional single-stage inverter during V2G mode. The stability analysis of the proposed controller is performed by defining a proper Lyapunov function. The functionality of the proposed nonlinear controller is first evaluated through simulation studies. The feasibility and effectiveness of the proposed control strategy is then validated using an industrial control card through a hardware-in-the-loop (HIL) experimental testbed.
\end{abstract}

Keywords: plug-in electric vehicle (PEV); sliding mode control (SMC); grid-to-vehicle (G2V); vehicle-to-grid (V2G); battery charger; modeling; control; three-phase bidirectional power converter

\section{Introduction}

Plug-in electric vehicles (PEVs) offer a promising solution to the worldwide concerns of rapid depletion of fossil fuel resources, environmental pollution, and the growing price of gasoline. Moreover, large-scale integration of PEVs provides ancillary services to the grid such as balancing load and generation, supporting the grid frequency and voltage profile, and eliminating transmission congestion [1-6]. However, large-scale integration of PEVs into the grid will increase the demand level and will affect the grid's power quality by introducing harmonic distortions. Therefore, a highly efficient bidirectional power electronics converter with high power factor and low total harmonic distortion (THD) is necessary to facilitate seamless operation in both grid-to-vehicle (G2V) and vehicle-to-grid (V2G) modes.

Utilizing bidirectional power converters for charging and discharging of the PEV's battery with the ultimate goal of achieving higher efficiency, improved power quality, higher power density, lower THD, reduced switching losses, less number of components, and cost-effective operation has widely been presented in the literature [7-16]. Different battery charger topologies and required infrastructures for PEV chargers have been reviewed in [17-19]. All of the proposed PEV battery charging systems can be broadly categorized in on-board and off-board chargers. Although, on-board chargers can be used anywhere due to their integration within the vehicle, they have some limitations in power range, weight, size, space, and the cost. Off-board chargers, on the other hand, offer higher power 
range in three levels (levels 1, 2, and 3) with less constraints of size and weight. Level 1 charging, also known as slow charging, can be done by plugging the electric vehicle to a convenience outlet of a private facility, while level 2 charging is utilized as the primary charging method for both private and public facilities. Both level 1 and level 2 chargers are usually implemented using single-phase unidirectional/bidirectional power electronic converters. However, the power level of integrated single-phase chargers is limited [20]. Three-phase battery charges, on the other hand, can operate at higher power levels and can fully charge EV battery packs in shorter time. Therefore, three-phase converters are utilized to implement level 3 chargers, also known as fast chargers, which are normally considered in public and commercial facilities. Three-phase chargers are bulkier and more expensive compared to single-phase chargers. However, the size and weight of three-phase high-power chargers can be significantly reduced by simplifying it to only a three-phase power electronics interface as a three-phase integrated charger [21,22].

PEVs' battery chargers can also be classified based on the number of power conversion stages into two main groups of single-stage and two-stage converters. Two-stage battery charger consists of a typical AC-DC converter in the first stage followed by an isolated bidirectional DC-DC converter as the second stage. The first stage rectifies and regulates the grid's AC voltage into the required DC voltage level, and the second stage isolates the output from the DC-link and the grid [23-26]. Single-stage topologies, on the other hand, process the power in a multifunctional fashion only in one power converter stage; therefore, they take advantage of lower number of components, which makes them more cost effective [27]. Unlike single-stage topologies, two-stage battery charges suffer from more complex controller and higher number of switches, which will in turn increase the cost and switching losses. For example, the authors in [28] utilized total of 18 switches and diodes along with a relatively complex controller. Similar complexity issue of the integration of 16 switches can also be observed in the implementation of a switched capacitor converter proposed in [29]. Although the number of switching elements has been reduced in [30], it still has significantly complex and computationally intensive controller due to interactions between six sub-controllers. Therefore, minimizing the number of switching elements is absolutely crucial to improve the converter's efficiency as demonstrated in [31]. Furthermore, most of existing complex topologies of power electronics technologies $[32,33]$ have utilized different types of linearized mathematical models such averaged model, small signal model, state-space model, and linearized transfer function model [34-37] in the design process of the controllers. Variations in system parameters, unmodeled dynamics, and/or oversimplification of the models by linearizing complex nonlinear systems can not only deteriorate the performance of the controller specifically in practical applications and harsh industrial environments, but it can also generate faulty conditions in which the stability of feedback control systems may be compromised. Unlike these controllers, sliding-mode control technique is robust to measurement/shift noises, modeling discrepancies, and variations in system parameters due to its natural robustness, excellent dynamic response, capability for system order reduction, and feasibility of modeling nonlinear power converters. Furthermore, sliding-mode controller is easier to implement with less computational burden, which makes it a great choice for real-time practical controller.

To this end, we have employed the inherited nonlinear robust nature of the sliding-mode control technique towards designing a precise and real-time hybrid feedback configuration in both continuous and discrete modes to ensure the stability and high performance of our controller despite the modeling discrepancies, variations in system parameters, disturbances and perturbations in harsh industrial environments and practical applications. Therefore, our contribution is proposing a proper three-dimensional sliding surface to design a stable, precise, and real-time practical controller that is easier to implement with less computational burden using a simple basic three-phase power electronic circuit to be used as an integrated PEV battery charger. The proposed three-dimensional nonlinear sliding-mode controller is designed to enforce a pseudo-resistive behavior between input voltage and current of each phase of the three-phase system. Single-stage topology of the utilized converter along with the proposed controlled switching pattern minimizes the switching losses, which in turn 
increases the efficiency of the converter. The proposed control strategy and switching regime enable the utilized bidirectional three-phase single-stage converter to perform multiple functions. When the input resistance for each phase of the three-phase converter, as the controller's set point, is set and maintained to a positive value, the converter operates as a power factor correction circuit, bridgeless boost converter and a rectifier during charging (G2V) mode. Similarly, for a negative desired input resistance, the converter operates as a conventional single-stage inverter during discharging (V2G) mode. The proposed controller and switching regime guarantee that the power factor of proposed system is maintained at unity in both G2V and V2G modes. To formulate the stability condition of the proposed nonlinear controller along with the utilized bidirectional three-phase single-stage converter, a Lyapunov function is proposed and employed. For brevity, isolation transformers or power electronic interfaces for the input and output stages of the utilized converter are not considered in the proposed system model. Moreover, the grid synchronization and interaction among PEVs are excluded in this work.

The rest of this paper is organized as follows. In Section 2, the principle operation of the three-phase converter and its dynamic model is presented for both charging and discharging modes. The proposed nonlinear control strategy is described in Section 3. Further, the stability analysis of the proposed controller using a Lyapunov function is presented in this section. In Section 4, the simulation and experimental results are presented, which validate the effectiveness and feasibility of the proposed nonlinear control strategy and switching regime when applied to a bidirectioanl three-phase single-stage battery charger. Finally, conclusions are drawn in Section 5.

\section{Operation Principle and Dynamic Model of the Bidirectional Three-Phase Converter}

Figure 1 illustrates the bidirectional three-phase single-stage converter utilized in this study. It is assumed that the top level switches, i.e, $Q_{a, \text { top }}, Q_{b, t o p}$, and $Q_{c, \text { top }}$ are switching on/off with the control signals $u_{a}, u_{b}$, and $u_{c}$, respectively, generated by the proposed nonlinear controller. The bottom level switches, i.e., $Q_{a, b o t}, Q_{b, b o t}$, and $Q_{c, b o t}$ are switched on/off according to the status of the corresponding top level switches. In other words, when one of the top level switches is turned on, the corresponding bottom level switch is turned off and vice versa. Therefore, there are total of eight individual switching modes as summarized in Table 1. As it is shown in this table, when the control signal is " 1 ", the corresponding top level switch is on, and when the control signal is " -1 ", the corresponding switch from top level of the converter is off. To find the complete dynamic model of the utilized converter, the dynamics of the circuit for all different modes of operation should be derived. Figure 2 illustrates the operation Mode 1 and all other modes of operation are not shown here for brevity. Using the Kirchhoff's circuit laws, we have

$$
\left\{\begin{array}{l}
\frac{d i_{a}(t)}{d t}=\frac{1}{3 L}\left(2 v_{a}(t)-v_{b}(t)-v_{\mathcal{c}}(t)\right)-\frac{2}{3 L} V_{B}, \\
\frac{d i_{b}(t)}{d t}=\frac{1}{3 L}\left(-v_{a}(t)+2 v_{b}(t)-v_{\mathcal{c}}(t)\right)+\frac{1}{3 L} V_{B}, \\
\frac{d i_{c}(t)}{d t}=\frac{1}{3 L}\left(-v_{a}(t)-v_{b}(t)+2 v_{\mathcal{c}}(t)\right)+\frac{1}{3 L} V_{B},
\end{array}\right.
$$

where $v_{a}(t), v_{b}(t)$, and $v_{c}(t)$ are the phase voltages; $i_{a}(t), i_{b}(t)$, and $i_{c}(t)$ represent the phase currents; and $V_{B}$ indicates the battery voltage. Moreover, $L$ represents the inductor value for each phase, which is assumed to be the same for all three phases. For brevity, the argument $t$ for all parameters is dropped in the rest of this paper. Similar dynamic model can be derived for Mode 6 of operation, in which only the sign of last term in each equation presented in (1) has been changed as

$$
\left\{\begin{array}{l}
\frac{d i_{a}}{d t}=\frac{1}{3 L}\left(2 v_{a}-v_{b}-v_{c}\right)+\frac{2}{3 L} V_{B} \\
\frac{d t_{b}}{d t}=\frac{1}{3 L}\left(-v_{a}+2 v_{b}-v_{c}\right)-\frac{1}{3 L} V_{B} \\
\frac{d c_{c}}{d t}=\frac{1}{3 L}\left(-v_{a}-v_{b}+2 v_{c}\right)-\frac{1}{3 L} V_{B} .
\end{array}\right.
$$




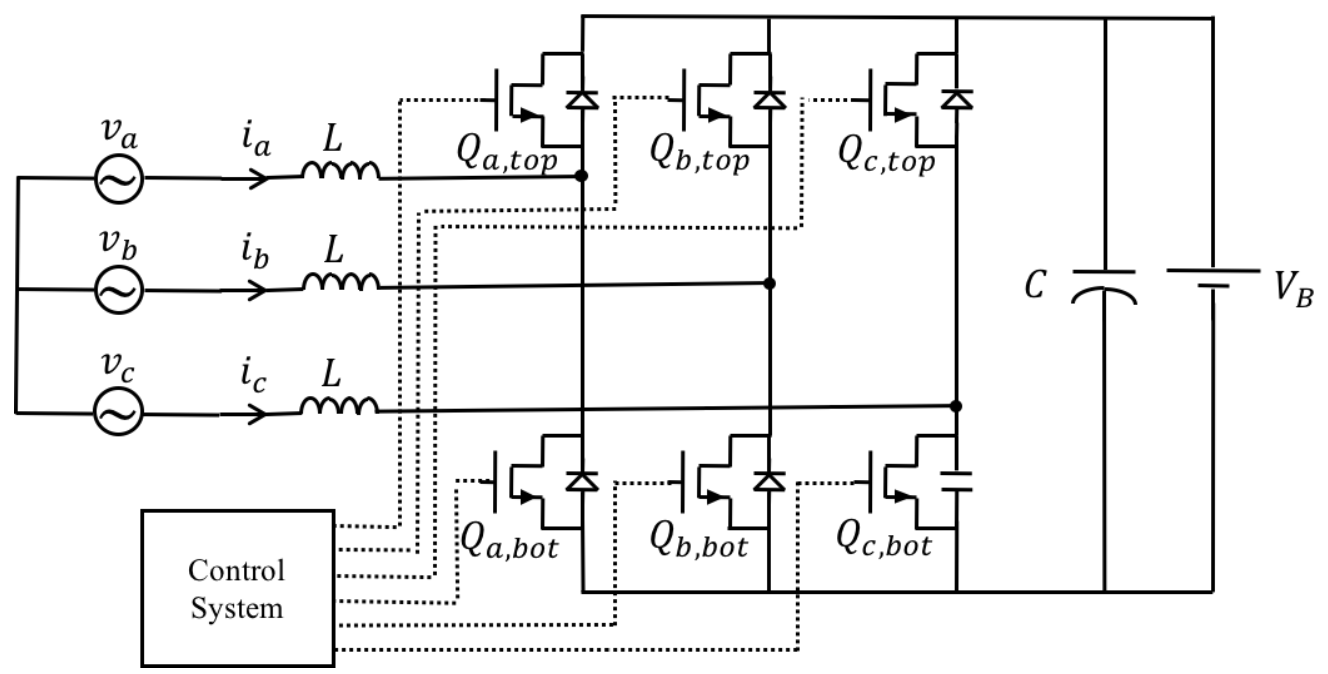

Figure 1. Bidirectional three-phase single-stage converter.

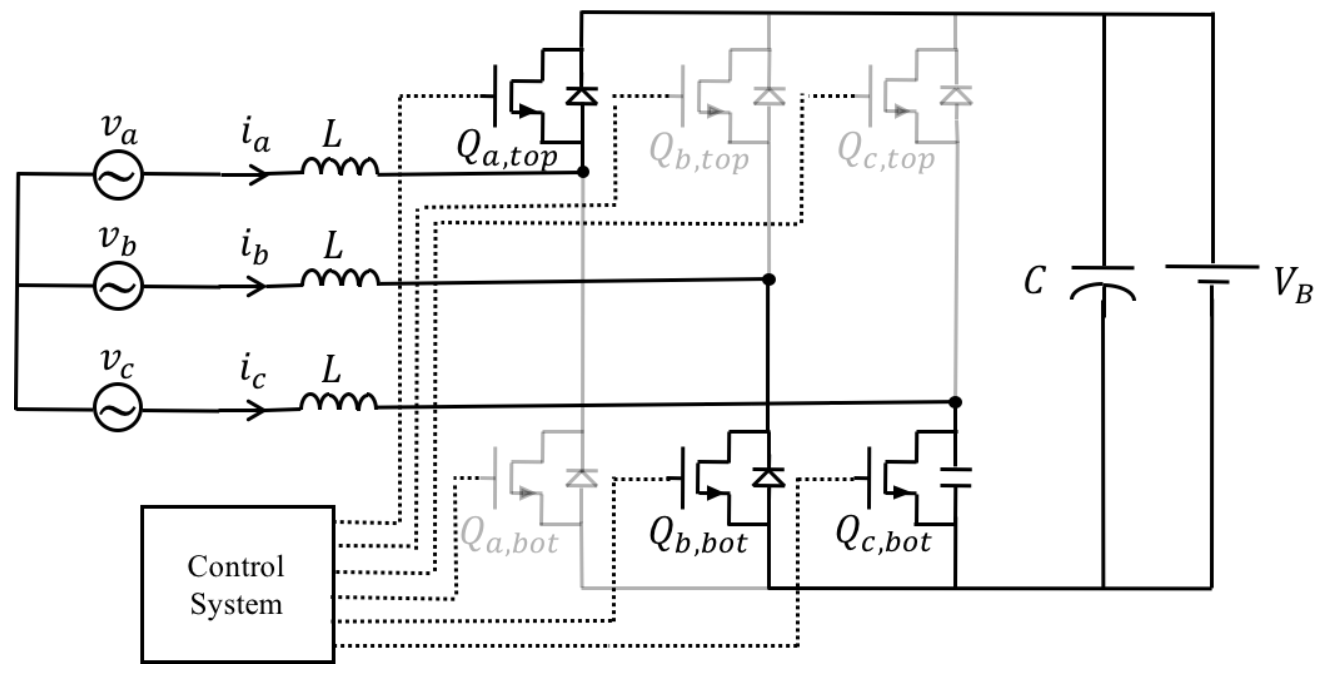

Figure 2. Mode 1 of operation.

Table 1. Switching arrangements in different modes of operation.

\begin{tabular}{ccccccc}
\hline Mode & $Q_{c, \text { top }}$ & $Q_{b, t o p}$ & $Q_{a, t o p}$ & $\boldsymbol{u}_{c}(t)$ & $\boldsymbol{u}_{\boldsymbol{b}}(\boldsymbol{t})$ & $\boldsymbol{u}_{\boldsymbol{a}}(\boldsymbol{t})$ \\
\hline 0 & OFF & OFF & OFF & -1 & -1 & -1 \\
\hline 1 & OFF & OFF & ON & -1 & -1 & 1 \\
\hline 2 & OFF & ON & OFF & -1 & 1 & -1 \\
\hline 3 & OFF & ON & ON & -1 & 1 & 1 \\
\hline 4 & ON & OFF & OFF & 1 & -1 & -1 \\
\hline 5 & ON & OFF & ON & 1 & -1 & 1 \\
\hline 6 & ON & ON & OFF & 1 & 1 & -1 \\
\hline 7 & ON & ON & ON & 1 & 1 & 1 \\
\hline & & & & & &
\end{tabular}

Similarly, the dynamics of the circuit for operation Modes 2 and 5 are obtained as

$$
\left\{\begin{array}{l}
\frac{d i_{a}}{d t}=\frac{1}{3 L}\left(2 v_{a}-v_{b}-v_{c}\right) \mp \frac{1}{3 L} V_{B} \\
\frac{d i_{b}}{d t}=\frac{1}{3 L}\left(-v_{a}+2 v_{b}-v_{c}\right) \pm \frac{2}{3 L} V_{B} \\
\frac{d i_{c}}{d t}=\frac{1}{3 L}\left(-v_{a}-v_{b}+2 v_{c}\right) \mp \frac{1}{3 L} V_{B}
\end{array}\right.
$$


where the upper signs of last term in each equation are for Mode 5. The dynamic models of the converter operating in Modes 3 and 4 can be also found as

$$
\left\{\begin{array}{l}
\frac{d i_{a}}{d t}=\frac{1}{3 L}\left(2 v_{a}-v_{b}-v_{c} \pm \frac{1}{3 L} V_{B}\right. \\
\frac{d i_{b}}{d t}=\frac{1}{3 L}\left(-v_{a}+2 v_{b}-v_{c}\right) \pm \frac{1}{3 L} V_{B} \\
\frac{d c_{c}}{d t}=\frac{1}{3 L}\left(-v_{a}-v_{b}+2 v_{c}\right) \mp \frac{2}{3 L} V_{B}
\end{array}\right.
$$

where the upper signs of last term in each equation are for Mode 4. Finally, for Modes 0 and 7 , we have

$$
\left\{\begin{array}{l}
\frac{d i_{a}}{d t}=\frac{1}{3 L}\left(2 v_{a}-v_{b}-v_{c}\right) \\
\frac{d i_{b}}{d t}=\frac{1}{3 L}\left(-v_{a}+2 v_{b}-v_{c}\right) \\
\frac{d i_{c}}{d t}=\frac{1}{3 L}\left(-v_{a}-v_{b}+2 v_{c}\right)
\end{array}\right.
$$

To find the closed form overall dynamic model of the utilized bidirectional three-phase single-stage converter for all modes of operation, (1)-(5) can be combined as

$$
\left\{\begin{array}{l}
\frac{d i_{a}}{d t}=\frac{1}{3 L}\left(2 v_{a}-v_{b}-v_{c}\right)-\frac{1}{6 L}\left(2 u_{a}-u_{b}-u_{c}\right) V_{B} \\
\frac{d i_{b}}{d t}=\frac{1}{3 L}\left(-v_{a}+2 v_{b}-v_{c}\right)-\frac{1}{6 L}\left(-u_{a}+2 u_{b}-u_{c}\right) V_{B} \\
\frac{d t_{c}}{d t}=\frac{1}{3 L}\left(-v_{a}-v_{b}+2 v_{c}\right)-\frac{1}{6 L}\left(-u_{a}-u_{b}+2 u_{c}\right) V_{B}
\end{array}\right.
$$

which can be further simplified in vector model format as [38]

$$
\frac{d}{d t} i=\frac{1}{3 L} K v-\frac{V_{B}}{6 L} K u,
$$

where $i=\left[\begin{array}{lll}i_{a} & i_{b} & i_{c}\end{array}\right]^{T}, v=\left[\begin{array}{lll}v_{a} & v_{b} & v_{c}\end{array}\right]^{T}, u=\left[\begin{array}{lll}u_{a} & u_{b} & u_{c}\end{array}\right]^{T}$ and $\mathrm{K}=\left[\begin{array}{ccc}2 & -1 & -1 \\ -1 & 2 & -1 \\ -1 & -1 & 2\end{array}\right]$.

The overall dynamic model of the converter derived in Equation (7) is then utilized in the proposed controller to enforce a positive or negative pseudo-resistance at the input terminals of the converter to facilitate charging or discharging modes, respectively.

\section{Nonlinear Sliding-Mode Controller}

In this section, we present the proposed nonlinear sliding-mode control strategy, which is applied to the bidirectional three-phase single-stage converter, whose dynamic model was derived earlier in Section 2 , as a PEV battery charger to facilitate both charging and discharging scenarios. The proposed nonlinear sliding-mode controller keeps the input voltage and current of each phase in the same phase in a way that the converter together with the battery could be seen as a three-phase resistive load. Therefore, the proposed controller sets and maintains a positive or negative desired resistance in real-time at the input terminals of the converter. Although the value of the desired resistance is calculated based on the circuit's components, the sign of desired resistance specifies the direction of power flow either from grid to the battery $(\mathrm{G} 2 \mathrm{~V})$ in charging mode when $R_{d}>0$ or from the PEV's battery to the utility grid (V2G) in discharging mode when $R_{d}<0$ as illustrated in Figure 3. Regulating and control of desired pseudo-resistance between the input voltage and current of each phase will result in lower harmonics and higher power factor. 


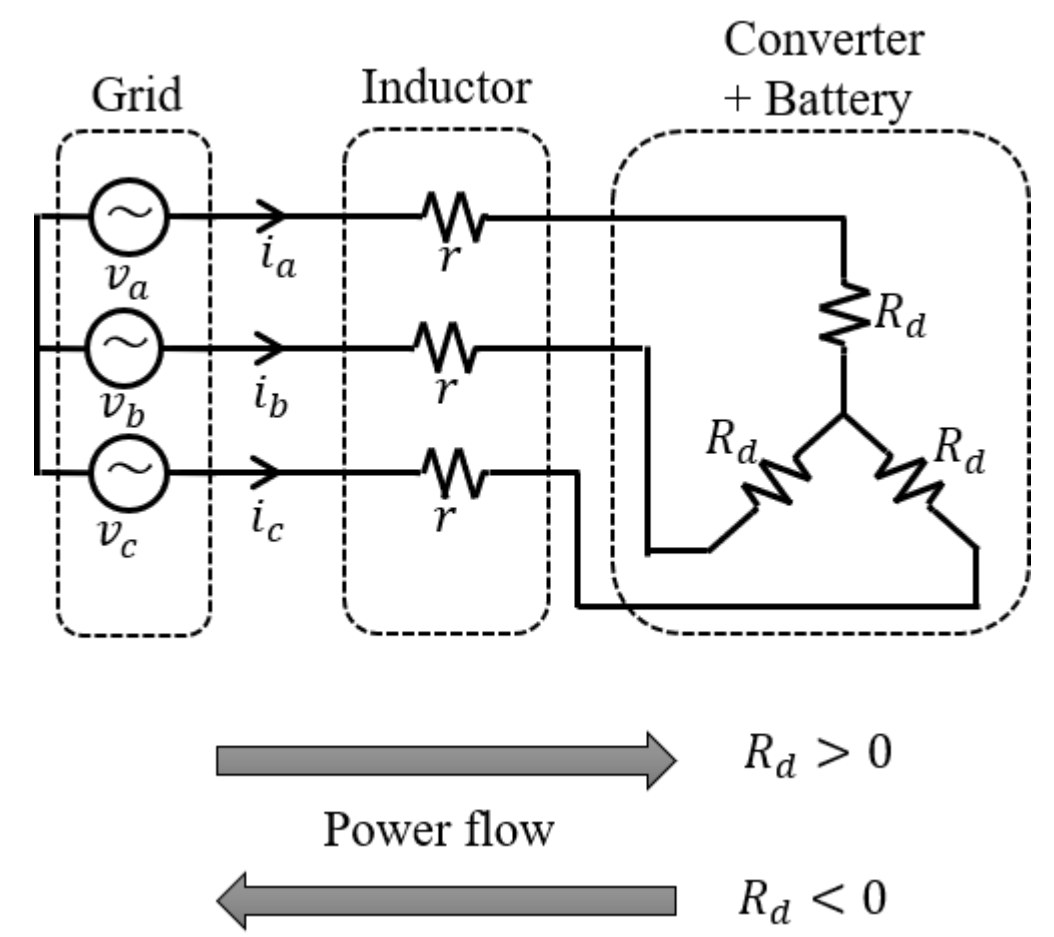

Figure 3. The equivalent resistive model of the proposed system.

Referring to Figure 3, the control goal can be redefined as regulating the input current of each phase compared to the corresponding phase voltage. In other words, based on the desired input resistance, $R_{d}$, the corresponding desired current for each phase can be calculated as

$$
i_{d}=\frac{1}{R_{d}+r} v,
$$

where $r$ is the internal resistance of the inductor for each phase and $i_{d}=\left[i_{d_{a}}, i_{d_{b}}, i_{d_{c}}\right]^{T}$ denotes the vector of desired current including all three phases.

The sliding surface, $s$, for the proposed sliding-mode controller is then defined as

$$
\sigma=i-i_{d}
$$

where $\sigma=\left[\sigma_{a}, \sigma_{b}, \sigma_{c}\right]^{T}$ represents the tracking error vector, which should converge to zero using the proposed control strategy. To do so, the control signal, $u$, for the proposed sliding-mode controller is defined as

$$
u=\operatorname{sign}(\sigma)
$$

For a three-phase system, the current of each phase is dependant on the current of the other two phases, i.e., $i_{a}+i_{b}+i_{c}=0$. Therefore,

$$
u_{c}= \begin{cases}-u_{a} & \left|\sigma_{a}\right| \geq\left|\sigma_{b}\right| \\ -u_{b} & \left|\sigma_{a}\right|<\left|\sigma_{b}\right|\end{cases}
$$

Given the dependencies of the phase currents, it should be noted that the switching arrangement presented on the first and last rows of Table 1 , which makes the gain matrix $K$ singular, does not take place in the system operation. 
To analyze the stability of the proposed sliding-mode control strategy, we define the positive definite function, $V$, as follows [39],

$$
V=\frac{1}{2} \sigma^{T} \sigma
$$

The derivative of $V$ in time domain is then obtained as follows

$$
\dot{V}=\sigma^{T} \dot{\sigma}=\sigma^{T}\left(\frac{1}{3 L} K v-\frac{V_{B}}{6 L} K u-\frac{1}{R_{d}+r} \dot{v}\right) .
$$

Let us define

$$
\psi=\frac{1}{3 L} K v-\frac{1}{R_{d}+r} \dot{v}+\frac{V_{B}}{6 L} J_{3} u,
$$

where $\psi=\left[\psi_{a}, \psi_{b}, \psi_{c}\right]^{T}$ and $J_{3}$ is a $3 \times 3$ all-ones matrix. Substituting (14) into (13), we have

$$
\dot{V}=\sigma^{T} \psi-\frac{V_{B}}{2 L} \sigma^{T} u,
$$

which should be negative to guarantee convergence of the proposed controller and stable operation.

The phase voltage vector, $v$, can be replaced by $v=A s(\omega)$, where $s(\omega)=$ $\left[\sin \omega t, \sin \left(\omega t-\frac{2 \pi}{3}\right), \sin \left(\omega t+\frac{2 \pi}{3}\right)\right]^{T}, \omega$ is the grid frequency, and $A$ is the grid voltage. The time derivative of the input voltage can be then written as follows

$$
\dot{v}=A \omega c(\omega),
$$

where $c(\omega)=\left[\cos \omega t, \cos \left(\omega t-\frac{2 \pi}{3}\right), \cos \left(\omega t+\frac{2 \pi}{3}\right)\right]^{T}$. Therefore, Equation (14) can be rewritten as

$$
\psi=\frac{A}{3 L} K s(\omega)-\frac{A \omega}{R_{d}+r} c(\omega)+\frac{V_{B}}{6 L} J_{3} u
$$

Using Equation (17), the value of $\psi$ for phase-a can be derived as follows

$$
\begin{aligned}
\psi_{a} & =\frac{A}{3 L}\left(2 \sin \omega t-\sin \left(\omega t-\frac{2 \pi}{3}\right)-\sin \left(\omega t+\frac{2 \pi}{3}\right)\right) \\
& -\frac{A \omega}{R_{d}+r} \cos \omega t+\frac{V_{B}}{6 L}\left(u_{a}+u_{b}+u_{c}\right),
\end{aligned}
$$

which can be rearranged as

$$
\begin{aligned}
\psi_{a} & =\frac{-A}{3 L}\left(\sin \omega t+\sin \left(\omega t-\frac{2 \pi}{3}\right)+\sin \left(\omega t+\frac{2 \pi}{3}\right)\right) \\
& +\frac{A}{L} \sin \omega t-\frac{A \omega}{R_{d}+r} \cos \omega t+\frac{V_{B}}{6 L}\left(u_{a}+u_{b}+u_{c}\right) .
\end{aligned}
$$

The first part of (19) is zero, therefore, it can be further simplified as

$$
\psi_{a}=\frac{A}{L} \sin \omega t-\frac{A \omega}{R_{d}+r} \cos \omega t+\frac{V_{B}}{6 L}\left(u_{a}+u_{b}+u_{c}\right) .
$$

The value of $\psi$ for the other two phases, i.e., $\psi_{b}$ and $\psi_{c}$, can be similarly derived. Therefore, using (20), $\psi$ for all three phases presented in (17), it can be written in vector format as

$$
\psi=\frac{A}{L} s(\omega)-\frac{A \omega}{R_{d}+r} c(\omega)+\frac{V_{B}}{6 L} J_{3} u
$$


Knowing

$$
a \cos x+b \sin x=\sqrt{a^{2}+b^{2}} \cos \left(x-\tan ^{-1} \frac{b}{a}\right),
$$

and utilizing it in (21), we have

$$
\widehat{\psi}=\frac{V_{B}}{6 L}+\sqrt{\left(\frac{A}{L}\right)^{2}+\left(\frac{A \omega}{R_{d}+r}\right)^{2}},
$$

where $\widehat{\psi}=\max (\psi)$ for each phase.

Integrating the previous results to establish the stability condition results in

$$
\dot{V} \leq-\left(\frac{V_{B}}{2 L}-\widehat{\psi}\right) \sqrt{2 V} .
$$

To make the sliding surface an attractive manifold, i.e., $\dot{V}<0$, the following inequality should exist between the input voltage amplitudes, desired resistances, and circuit parameters,

$$
\sqrt{\left(\frac{A}{L}\right)^{2}+\left(\frac{A \omega}{R_{d}+r}\right)^{2}}<\frac{V_{B}}{3 L} .
$$

Equation (25) guarantees existence of the conditions for zero tracking error and stable operation of the proposed system, when suitable battery size is selected.

A boundary for the desired input resistance of each phase, $R_{d}$, can be found based on the circuit components, such as inductance of each phase $L$ and battery voltage $V_{B}$, as follows

$$
\left|R_{d}\right| \geq \frac{3 A \omega L}{\sqrt{V_{B}^{2}-9 A^{2}}},
$$

where the internal resistance of the inductor for each phase, $r$, is ignored.

To avoid chattering in the area near or surrounding the operating point, which is a well-known issue of sliding-mode controller, a deadband function is implemented into the control strategy as shown in Figure 4. Utilizing this function, the controller will not change the control signal when the error is within the predefined boundary, which will in turn improve the performance and the speed of the sliding-mode controller.

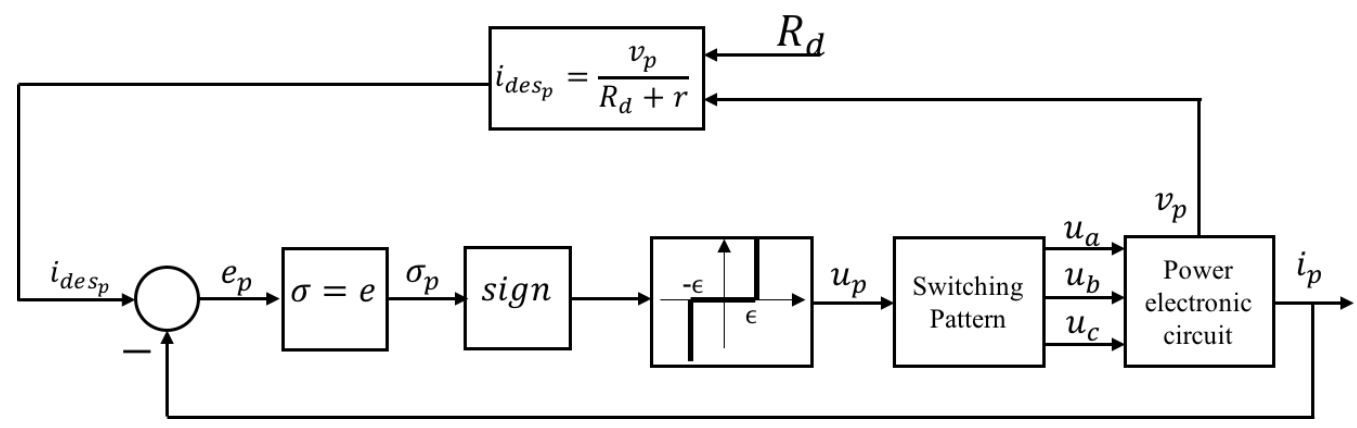

Figure 4. The block diagram of the proposed controller.

\section{Numerical and Experimental Studies}

The proposed three-dimensional nonlinear sliding-mode controller is applied to a three-phase converter testbed implemented in PSIM environment. The value of inductor for each phase is 
considered to be $0.01 \mathrm{H}$, the output capacitor is chosen to be $100 \mu \mathrm{F}$, and a lithium-ion battery with a rated voltage of $600 \mathrm{~V}$, representing the PEV's battery, is utilized in this testbed. The battery is connected to the utility grid with the frequency of $60 \mathrm{~Hz}$ and the voltage of $120 \mathrm{Vrms}$. The switching frequency is set to $10 \mathrm{kHz}$.

Figures 5 and 6 show the simulation results with the desired input resistance of $10 \Omega$ and $-10 \Omega$, respectively. It is evident from these figures that when the desired input resistance is positive, the power is transferred from the grid into the battery with unity power factor facilitating G2V mode of operation, in which PEV battery is charged. Similarly, for the negative input resistance of $-10 \Omega$, the power is transferred from the PEV battery into the grid facilitating V2G or discharging mode of operation. Moreover, the battery's state-of-charge (SOC) illustrated in Figures $5 c$ and $6 c$ confirm charging and discharging functionality of the proposed system.

Figure 7 demonstrates that the proposed control strategy can rapidly and accurately respond to a sudden change in the mode of operation. The system is operated in discharging mode for the first $0.1 \mathrm{~s}$, when the desired input resistance of the converter is set to $-10 \Omega$. At the time $t=0.1 \mathrm{~s}$, the desired input resistance is changed to $10 \Omega$ and the controller smoothly follows this sudden change in the mode of operation.

To investigate the effectiveness of the proposed control strategy in current harmonic reduction, THD was calculated for one phase (phase a) as 5.56\%, 6.64\%, and 5.52\% in charging, discharging, and step change from discharging to charging modes, respectively, which meet the IEC 61000-3-12 current harmonic limits.

To further evaluate the performance of the proposed controller experimentally, the proposed system is implemented on a hardware-in-the-loop (HIL) testbed as shown in Figure 8 . The testbed includes a Typhoon HIL602 real-time power electronics emulator, which allows us to emulate the power stage with up to $2 \mathrm{MHz}$ update rate and test the controller with 20ns PWM resolution. The power stage including the bidirectional three-phase converter and high power level battery are built in Typhoon HIL emulator environment. It is then connected to host PC via Ethernet or USB2.0, where identical power stage along with the proposed sliding-mode controller have been developed in PSIM environment. The controller developed in PSIM is then flashed onto the industrial TI TMS320F28335 control card using code composer studio (CCS). The control card captures the input voltage/current and desired input resistance of each phase in real-time. Based on the captured voltage and current of each phase and desired input resistance, the nonlinear sliding mode controller implemented in TI control card then generates and sends back the pulse width modulated (PWM) gate control signals to all six switches of the converter developed on the HIL system. For clarity, the captured input voltage and current waveforms of each phase of the utilized system in the HIL testbed are drawn in MATLAB.

Figure 9 shows the experimental results in charging mode when $R_{d}=10 \Omega$. Similarly, experimental results for discharging mode with $R_{d}=-10 \Omega$ are shown in Figure 10. Moreover, Figure 11 depicts the experimental results in the presence of sudden change of the controller set point from a negative to a positive value for the desired input resistance at $t=0.1 \mathrm{~s}$. From these figures, it is evident that experimental results closely match the simulation results and the theoretical modeling and analysis. Furthermore, it is shown that the controller can accurately provide the desired resistance in real-time even after a sudden change of operation mode from discharging to charging. 


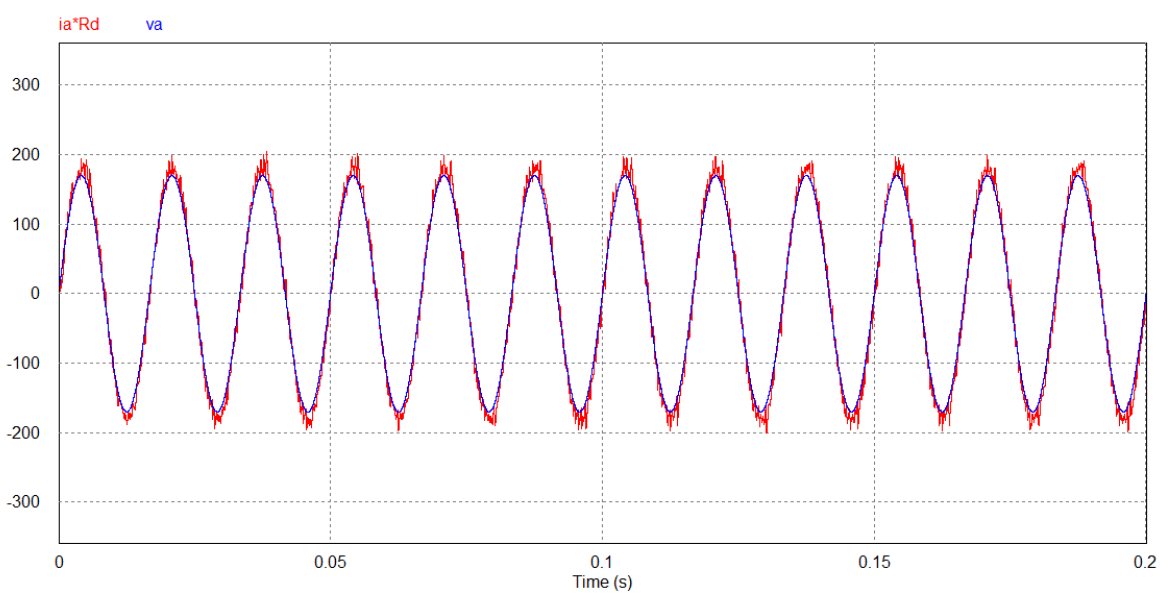

(a)
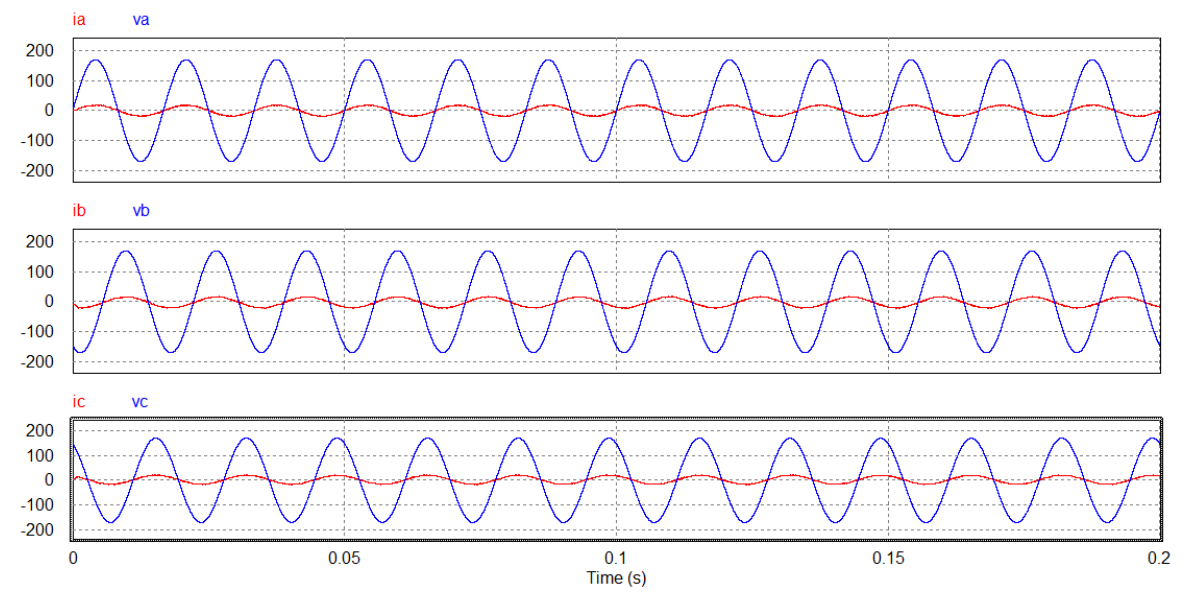

(b)

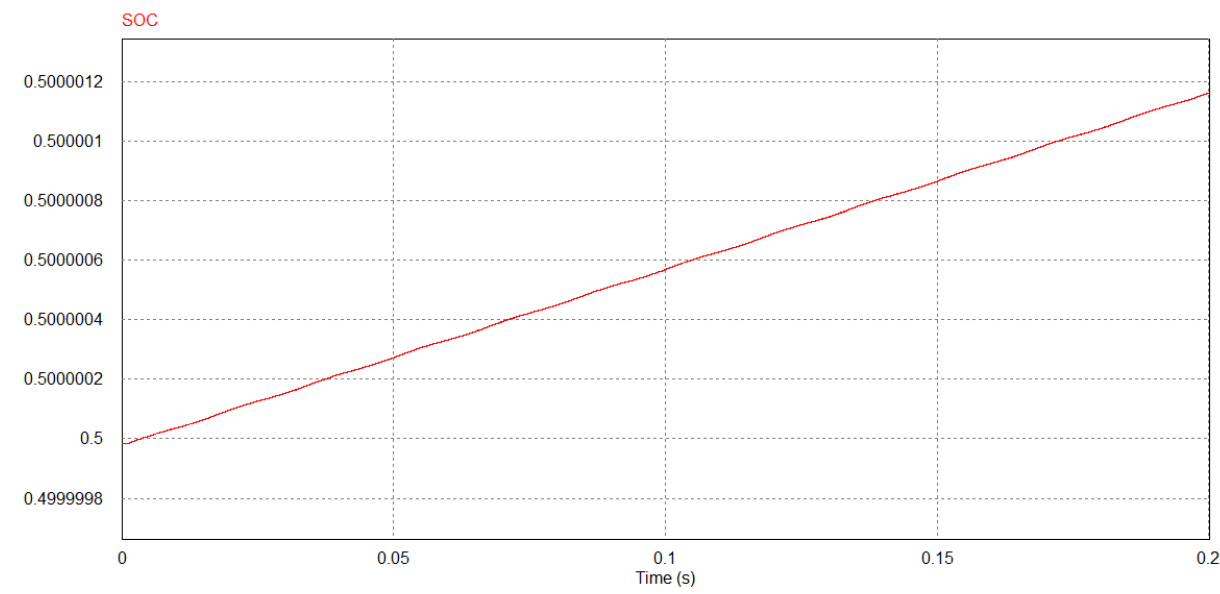

(c)

Figure 5. Simulation results for $R_{d}=10 \Omega$. (a) The voltage of Phase-a and its current multiplied by $R_{d}$. (b) The input voltage and current of each phase. (c) The battery state-of-charge (SOC). 


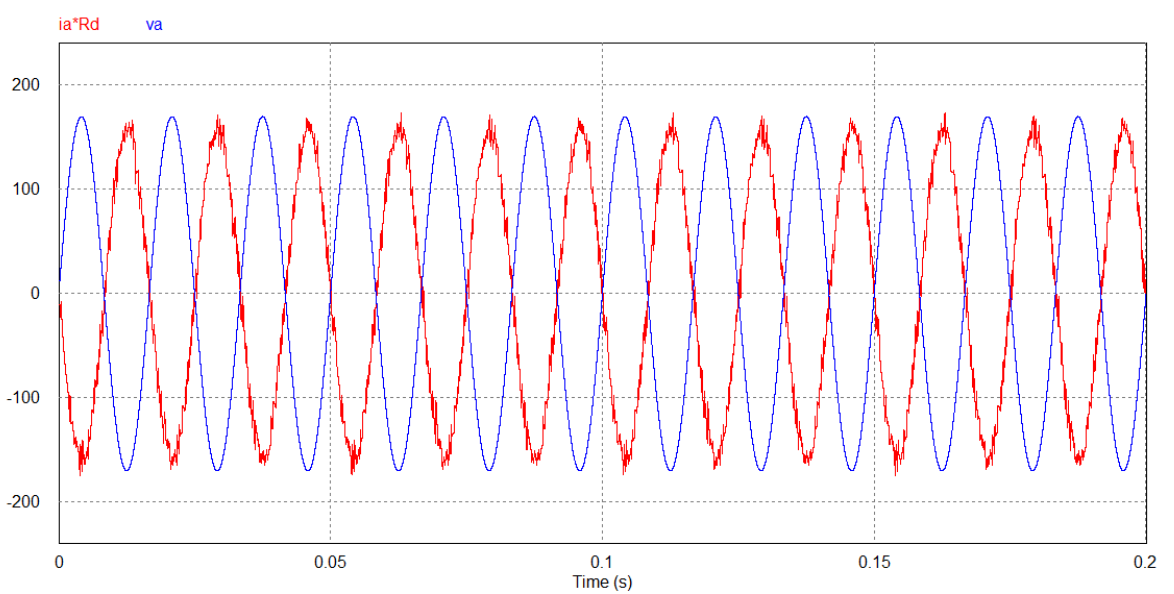

(a)
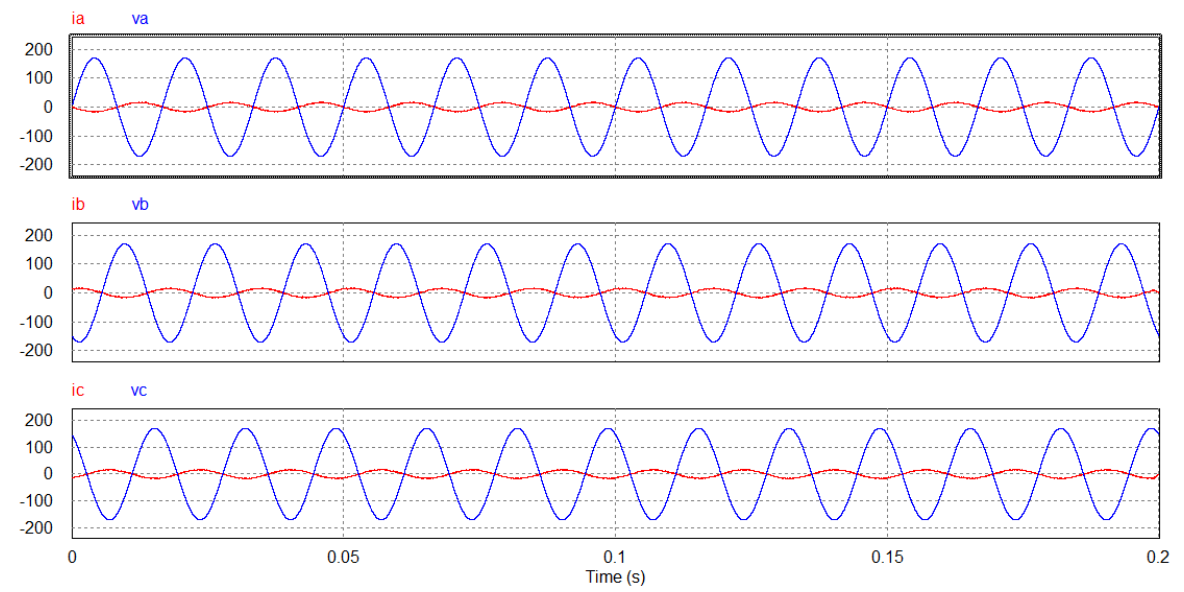

(b)

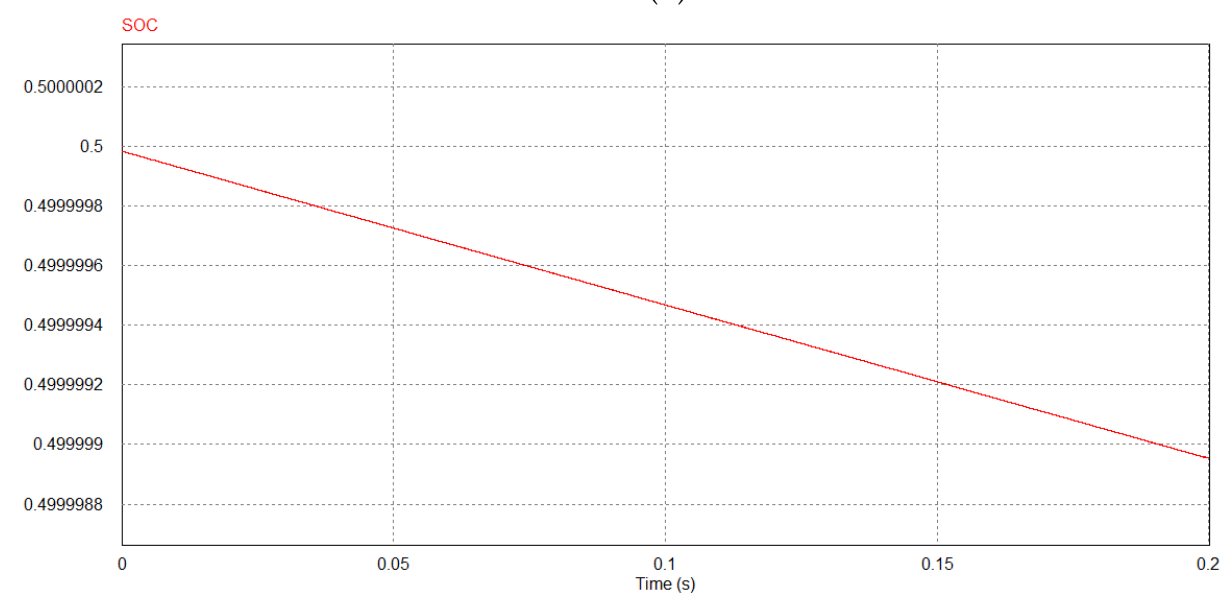

(c)

Figure 6. Simulation results for $R_{d}=-10 \Omega$. (a) The voltage of Phase-a and its current multiplied by $R_{d}$. (b) The input voltage and current of each phase. (c) The battery SOC. 


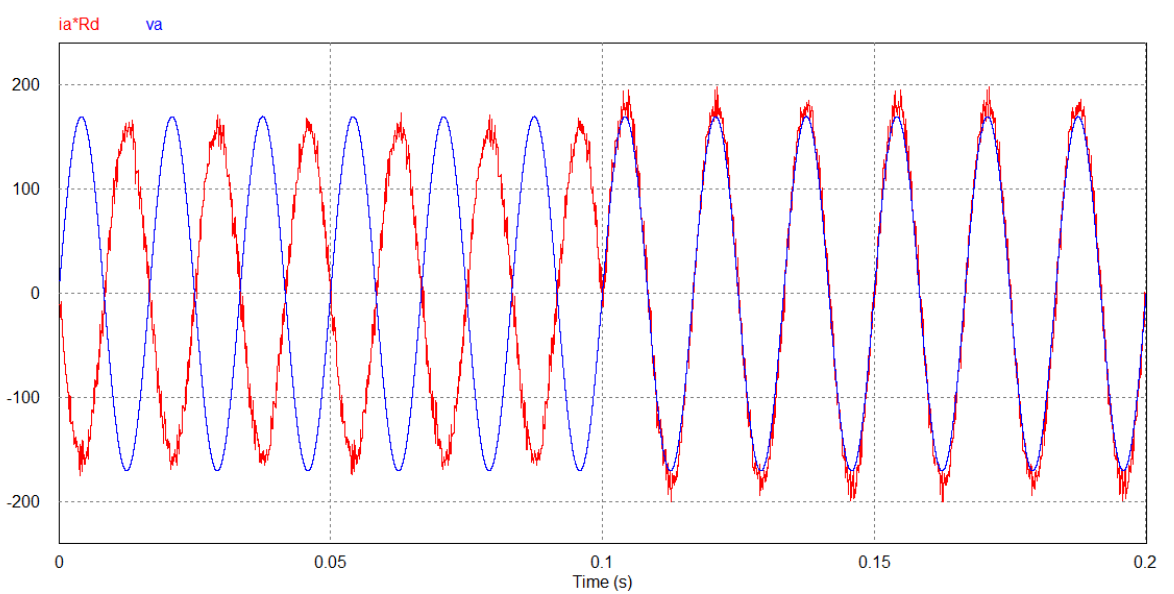

(a)
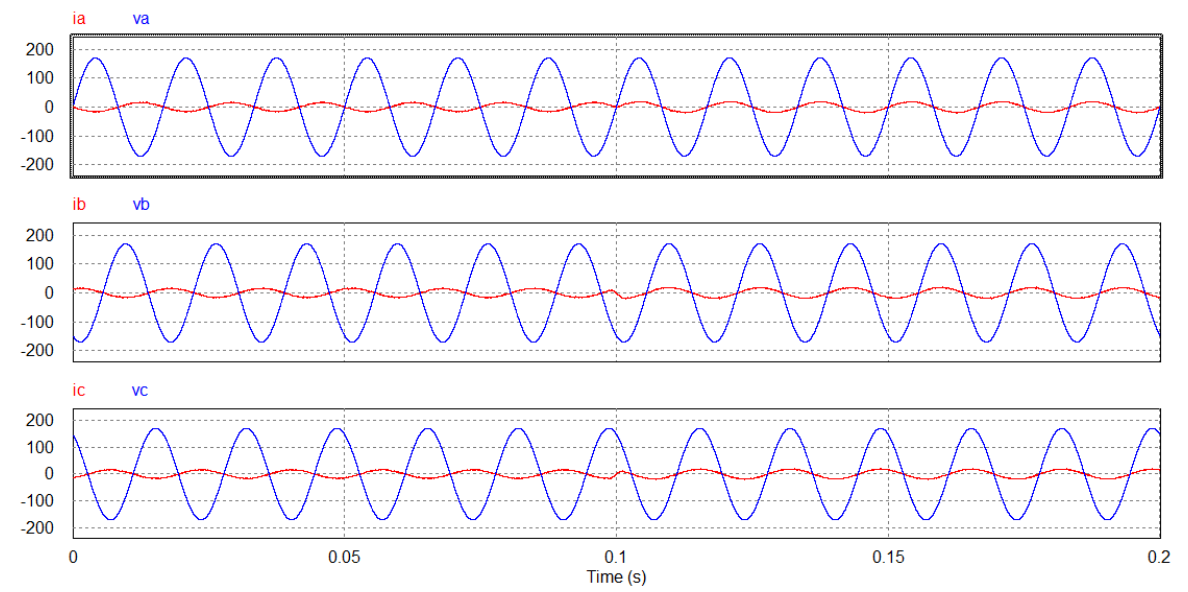

(b)

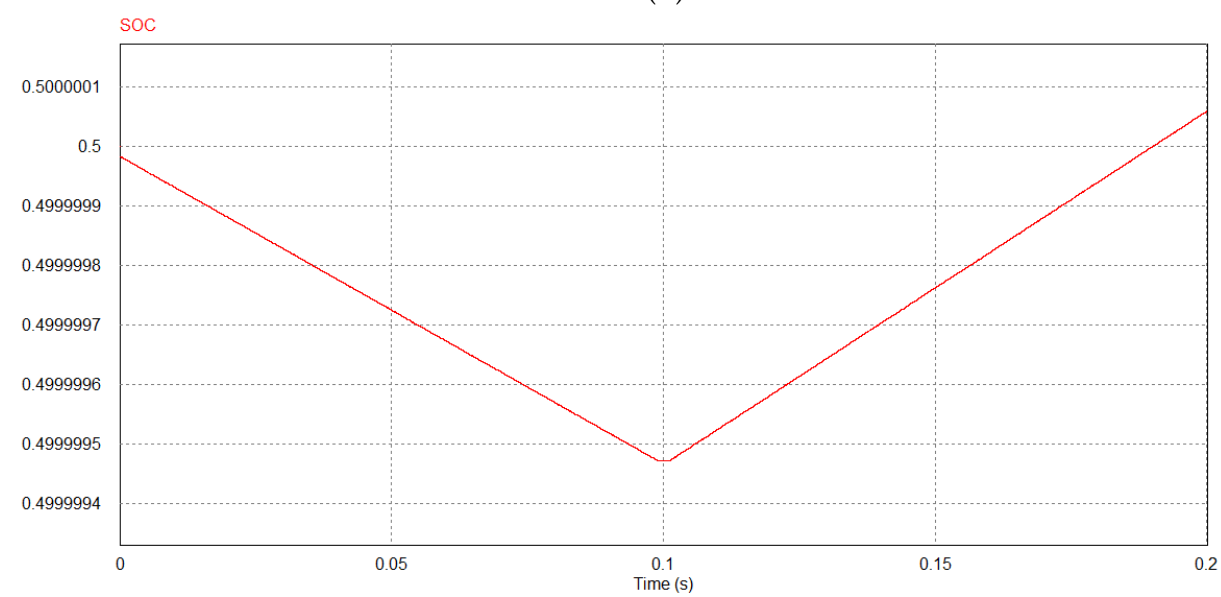

(c)

Figure 7. Simulation results for a sudden change in the mode of operation from discharging when $R_{d}=-10 \Omega$ to charging mode when $R_{d}=10 \Omega$. (a) The voltage of Phase-a and its current multiplied by $R_{d}$. (b) The input voltage and current of each phase. (c) The battery SOC. 


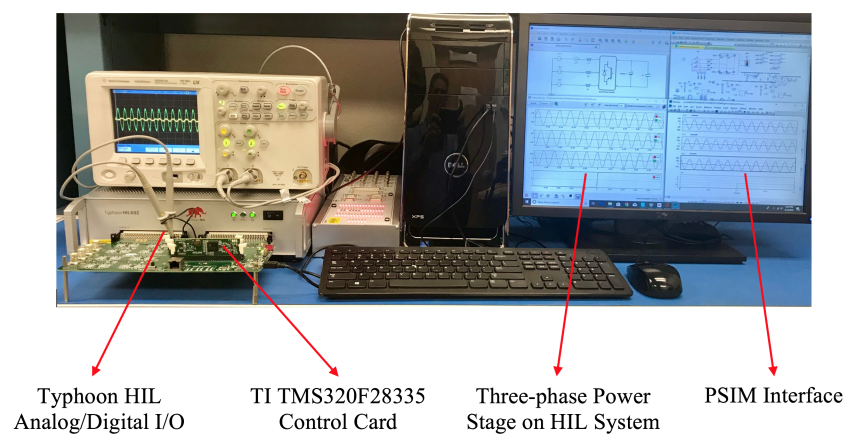

(a)

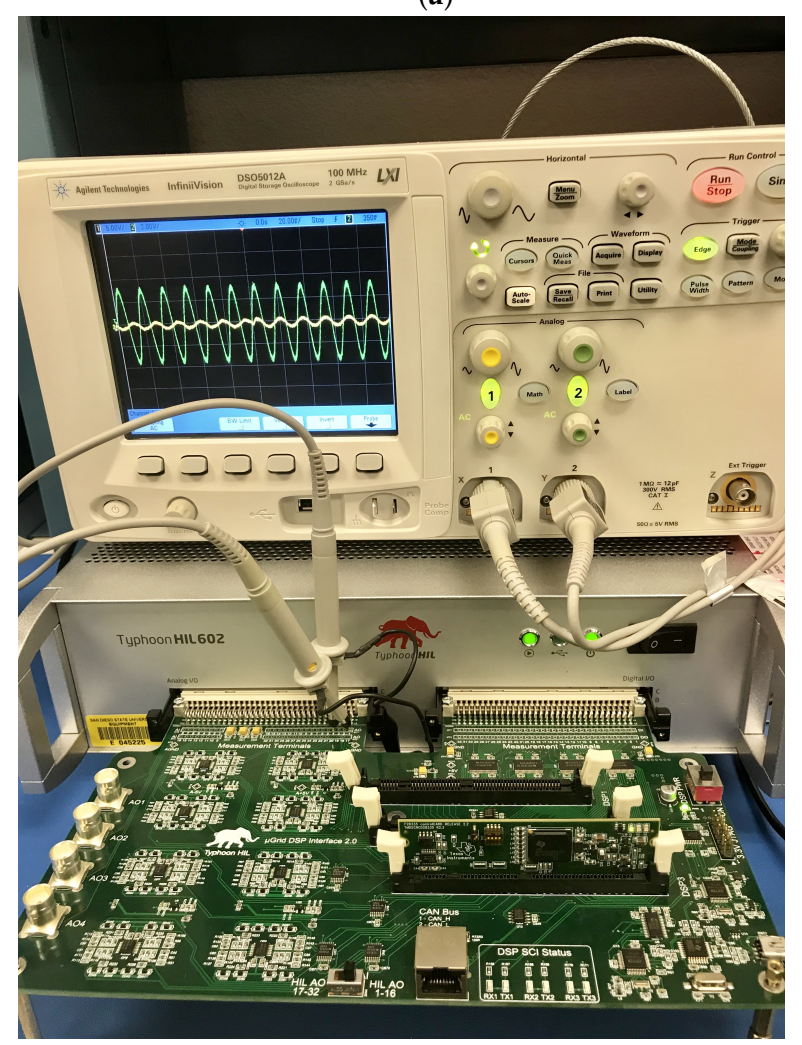

(b)

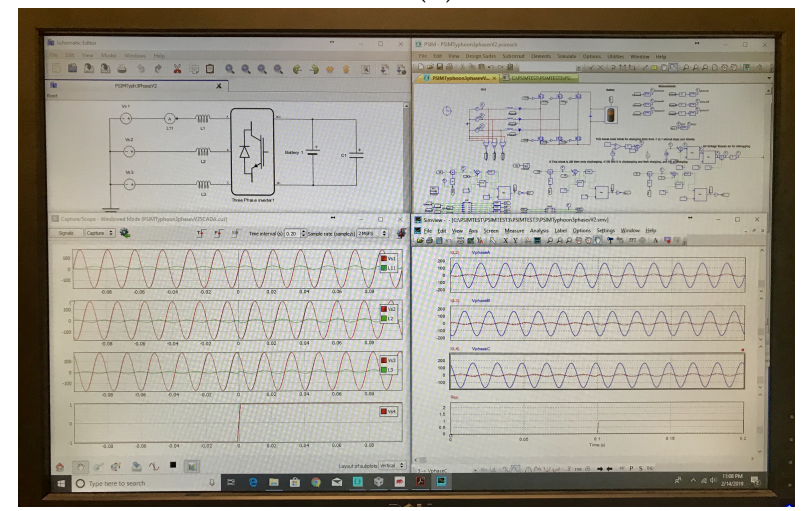

(c)

Figure 8. Experimental Set-up: (a) Set-up overview. (b) TI TMS320F28335 control card and oscilloscope showing input voltage and current of phase-a with step change in desired resistance from $-10 \Omega$ to $10 \Omega$. (c) PSIM interface and implemented power stage on the hardware-in-the-loop (HIL) system. 


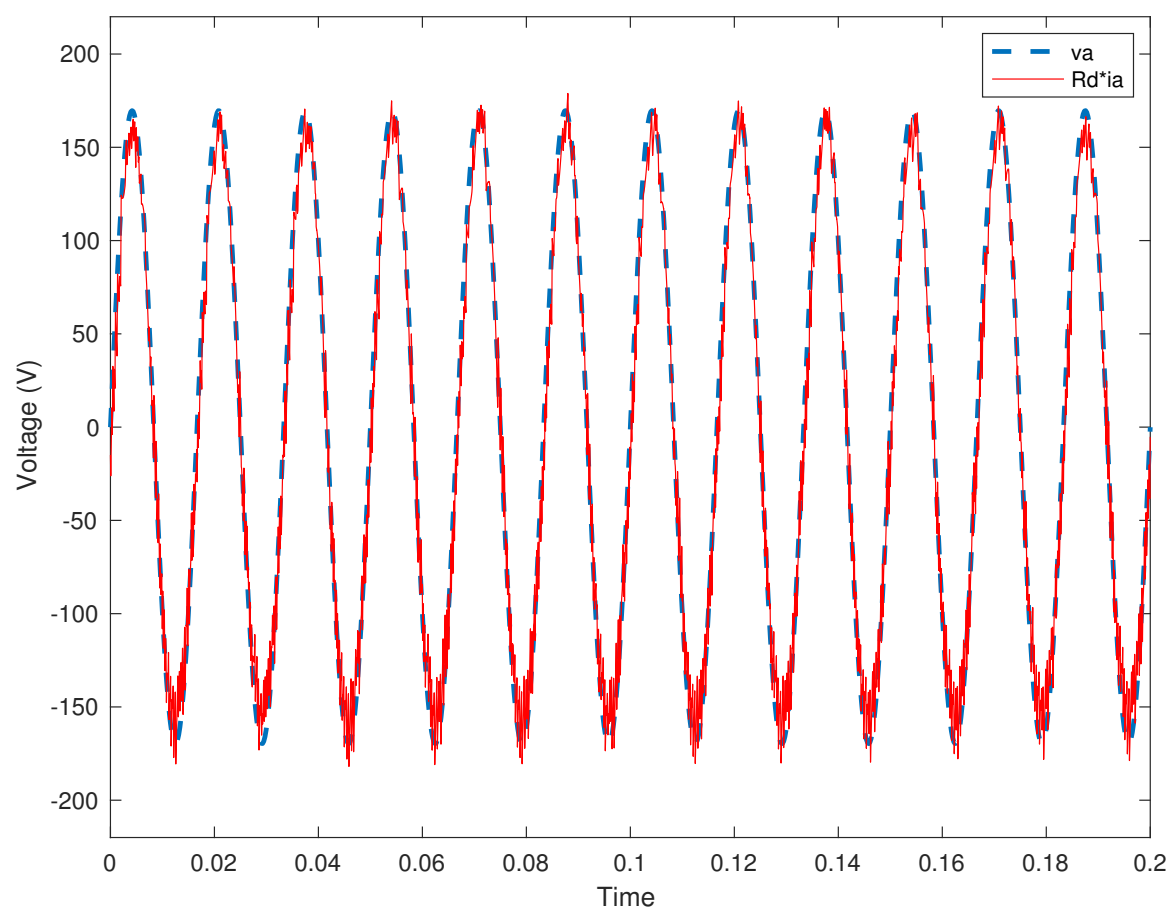

(a)
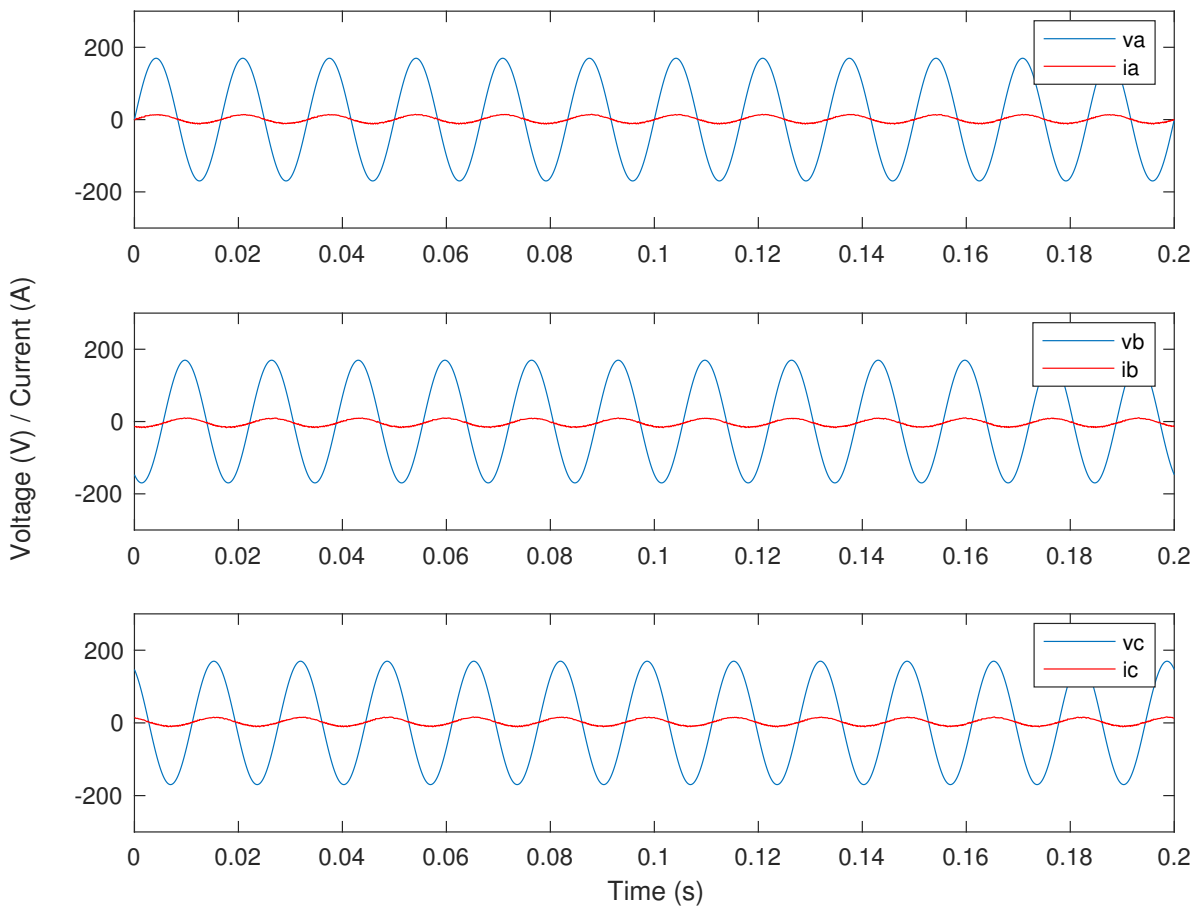

(b)

Figure 9. Experimental results for $R_{d}=10 \Omega$. (a) The voltage of Phase-a and its current multiplied by $R_{d}$. (b) The input voltage and current of each phase. 


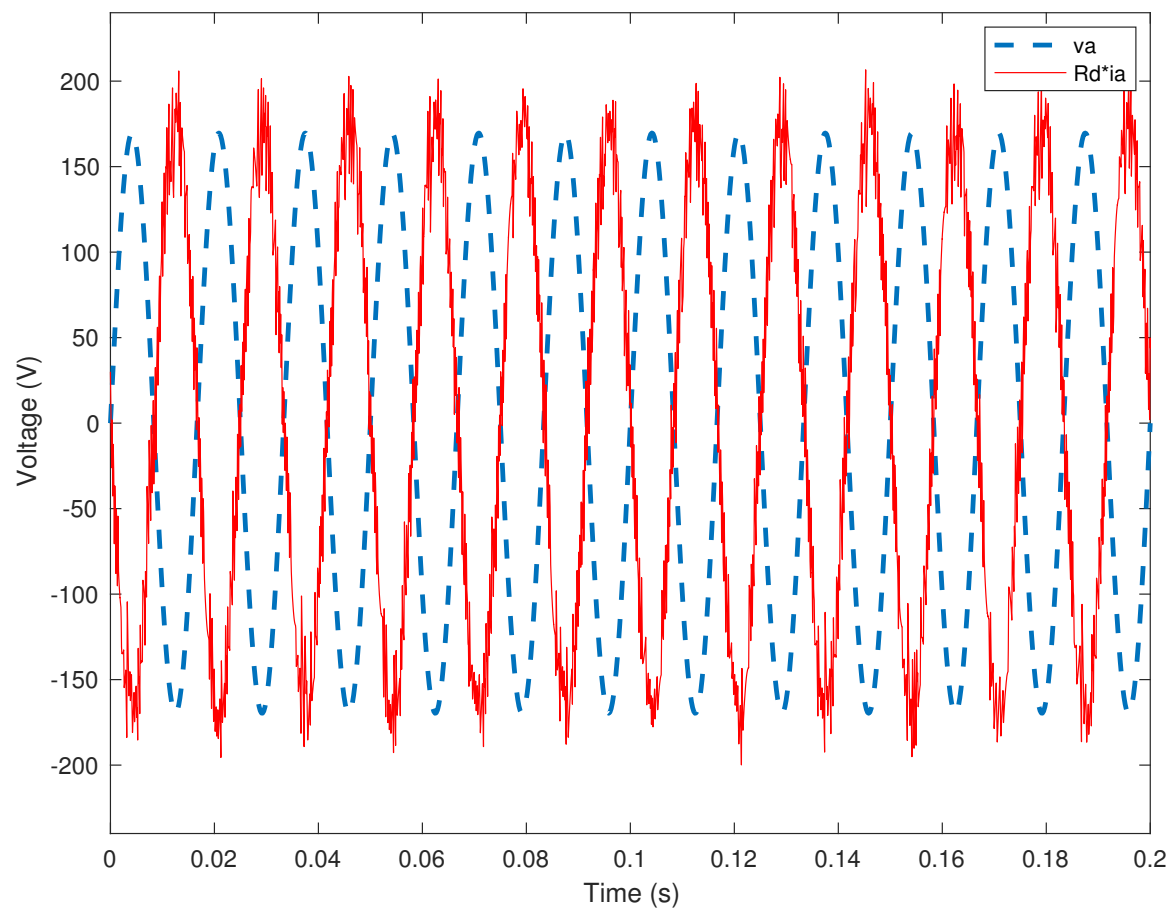

(a)

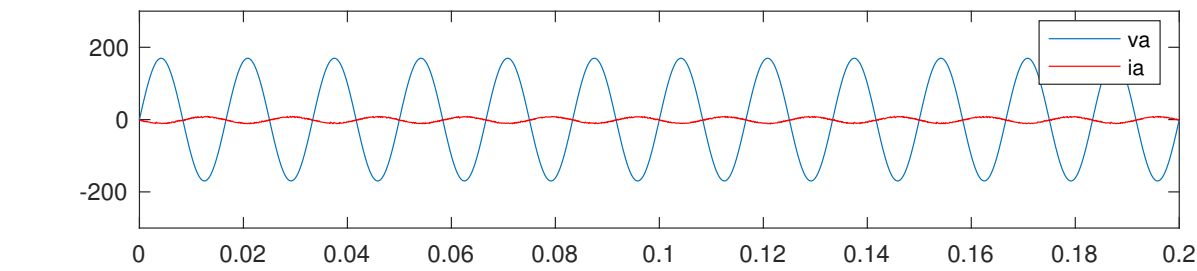

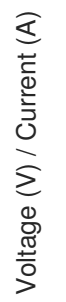
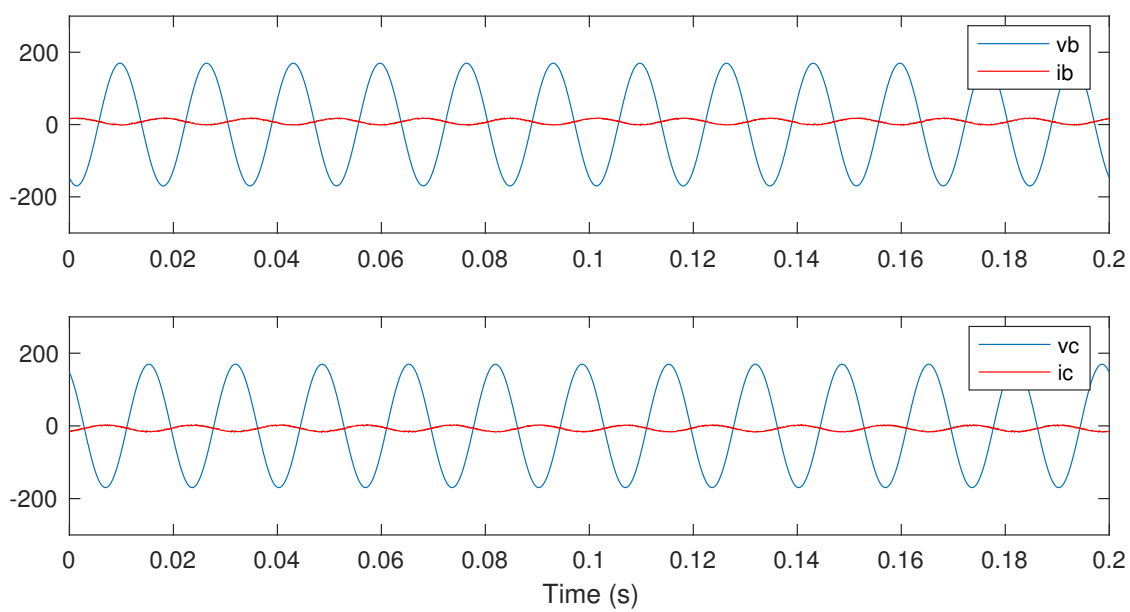

(b)

Figure 10. Experimental results for $R_{d}=-10 \Omega$. (a) The voltage of Phase-a and its current multiplied by $R_{d}$. (b) The input voltage and current of each phase. 


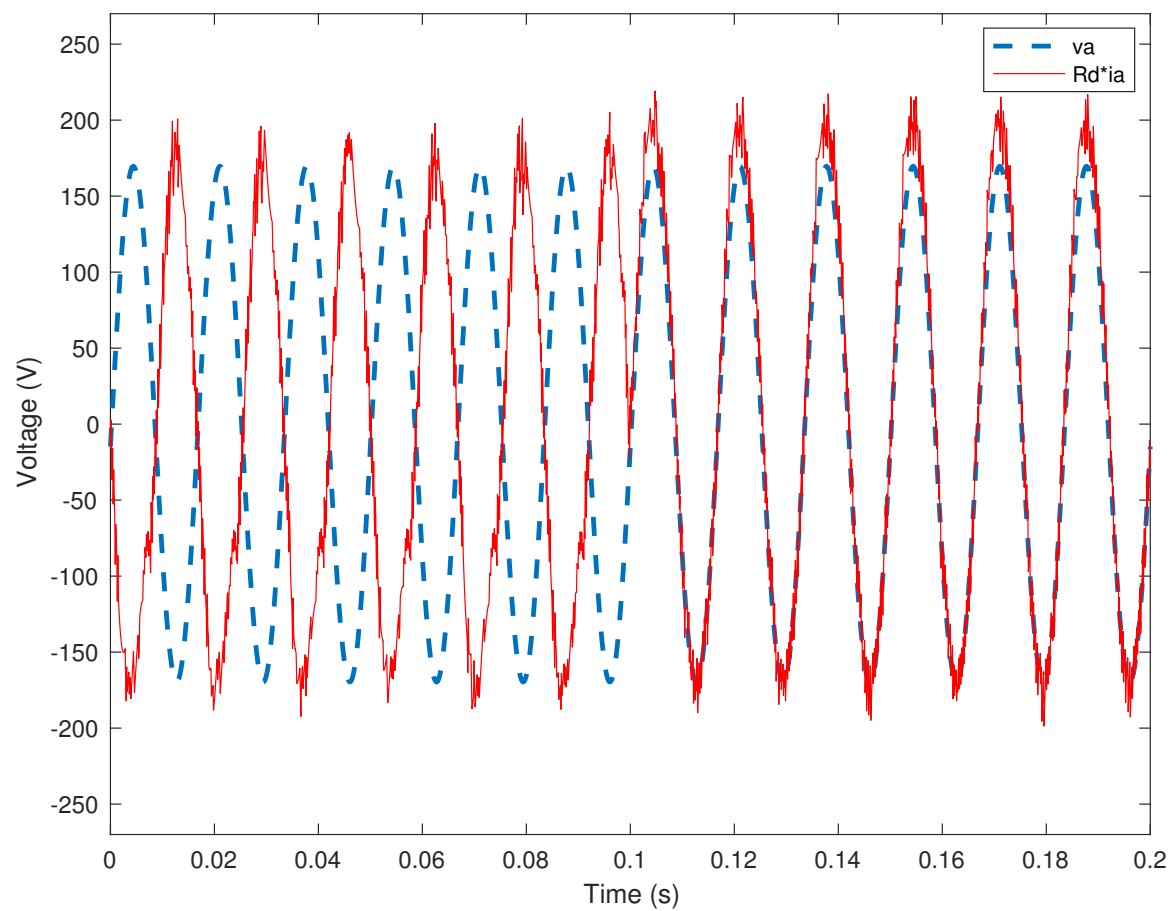

(a)
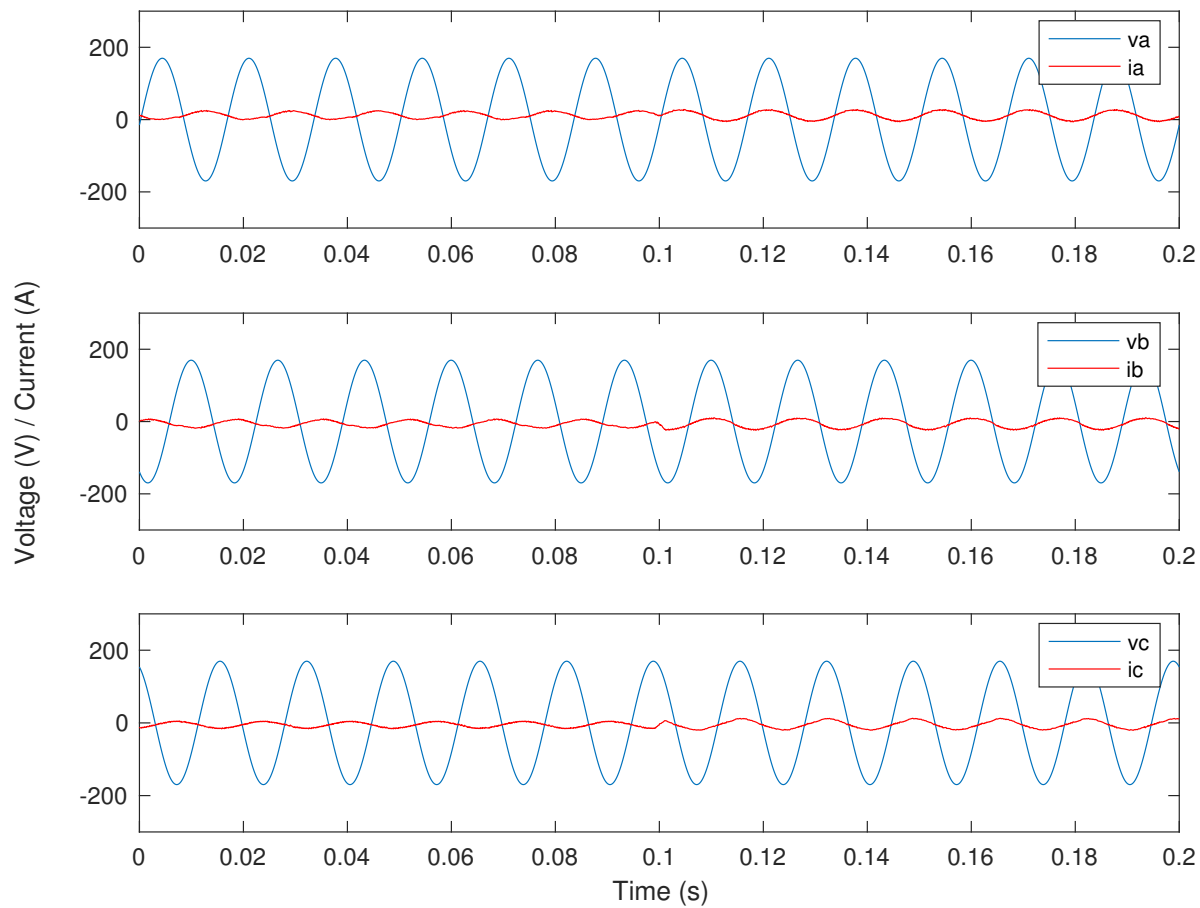

(b)

Figure 11. Experimental results for a sudden change in the mode of operation from discharging when $R_{d}=-10 \Omega$ to charging mode when $R_{d}=10 \Omega$. (a) The voltage of Phase-a and its current multiplied by $R_{d}$. (b) The input voltage and current of each phase. 


\section{Conclusions}

In this paper, a nonlinear sliding-mode control strategy was proposed for a three-phase converter as a PEV battery charger for bidirectional power flow from and to the utility grid. The proposed nonlinear sliding-mode controller sets and regulates a resistive relationship between the input voltage and current of each phase of the system in real-time. Furthermore, the stability condition of the proposed controller was formulated using a Lyapunov function. The presented simulation and experimental results validated the feasibility and effectiveness of the proposed controller in all modes of operation, i.e., charging, discharging, and sudden changes from one mode to the other mode. The bidirectional functionality of the utilized converter enabled by the proposed control strategy, specifically in V2G mode, allows the grid operator to take advantage of PEVs' ancillary services for the grid voltage and frequency regulation. This is very critical more specifically in islanded power grid, which is the subject of our future research.

Author Contributions: Conceptualization, R.S. and Y.M.R.; Methodology, R.S. and Y.M.R.; software, R.S. and Y.M.R.; Validation, R.S., Y.M.R., and P.F.; Formal analysis, R.S., Y.M.R., and P.F.; Investigation, R.S., Y.M.R., and P.F.; Resources, R.S.; Writing—original draft preparation, R.S. and Y.M.R.; Writing—review and editing, R.S., Y.M.R., and P.F.; Visualization, R.S., Y.M.R., and P.F.; supervision, R.S.; project administration, R.S.; Funding acquisition, none. All authors have read and agreed to the published version of the manuscript.

Funding: This research received no external funding.

Conflicts of Interest: The authors declare no conflict of interest.

\section{Abbreviations}

The following abbreviations are used in this manuscript:

$\begin{array}{ll}\text { PEV } & \text { Plug-in Electric Vehicle } \\ \text { SMC } & \text { Sliding Mode Control } \\ \text { G2V } & \text { Grid-to-Vehicle } \\ \text { V2G } & \text { Vehicle-to-Grid } \\ \text { THD } & \text { Total Harmonic Distortion } \\ \text { DC } & \text { Direct Current } \\ \text { AC } & \text { Alternating Current }\end{array}$

\section{References}

1. Latifi, M.; Sabzehgar, R.; Rasouli, M. Reactive power compensation using plugged-In electric vehicles for an ac power grid. In Proceedings of the IECON 2018-44th Annual Conference of the IEEE Industrial Electronics Society, Washington, DC, USA, 21-23 October 2018; IEEE: Piscataway, NJ, USA, 2018; pp. 4986-4991.

2. Kesler, M.; Kisacikoglu, M.C.; Tolbert, L.M. Vehicle-to-grid reactive power operation using plug-in electric vehicle bidirectional offboard charger. IEEE Trans. Ind. Electron. 2014, 61, 6778-6784. [CrossRef]

3. Latifi, M.; Sabzehgar, R.; Rasouli, M.; Fajri, P. Active and reactive power compensation using a pev-Based three-level capacitor clamped inverter. In Proceedings of the TPEC 2019-3rd Annual Texas Power and Energy Conference, College Station, TX, USA, 7-8 February 2019; IEEE: Piscataway, NJ, USA, 2019; pp. 1-6.

4. Haidar, A.M.; Muttaqi, K.M. Behavioral characterization of electric vehicle charging loads in a distribution power grid through modeling of battery chargers. IEEE Trans. Ind. Appl. 2016, 52, 483-492. [CrossRef]

5. Kazemi, M.A.; Sabzehgar, R.; Rasouli, M. An optimized scheduling strategy for plugged-in electric vehicles integrated into a residential smart microgrid for both grid-tied and islanded modes. In Proceedings of the 2017 IEEE 6th International Conference on Renewable Energy Research and Applications (ICRERA), San Diego, CA, USA, 5-8 November 2017; IEEE: Piscataway, NJ, USA, 2017; pp. 251-256.

6. Sabzehgar, R.; Kazemi, M.A.; Rasouli, M.; Fajri, P. Cost optimization and reliability assessment of a microgrid with large-scale plug-in electric vehicles participating in demand response programs. Int. J. Green Energy 2020, 17, 127-136. [CrossRef]

7. Liu, Z.; Li, B.; Lee, F.C.; Li, Q. High-efficiency high-density critical mode rectifier/inverter for WBG-devicebased on-board charger. IEEE Trans. Ind. Electron. 2017, 64, 9114-9123. [CrossRef] 
8. Singh, A.K.; Pathak, M.K. Single-phase bidirectional ac/dc converter for plug-in electric vehicles with reduced conduction losses. IET Power Electron. 2017, 11, 140-148. [CrossRef]

9. Shafiei, N.; Ordonez, M.; Tokaldani, M.A.S.; Arefifar, S.A. PV Battery Charger Using an L3C Resonant Converter for Electric Vehicle Applications. IEEE Trans. Transp. Electrif. 2018, 4, 108-121. [CrossRef]

10. Sabzehgar, R.; Roshan, Y.M. Modelling and control of a bidirectional single-phase single-stage converter for plug-in electric vehicles. Int. J. Electr. Hybrid Veh. 2018, 10, 197-208. [CrossRef]

11. Prasanna, U.R.; Singh, A.K.; Rajashekara, K. Novel bidirectional single-phase single-stage isolated AC-DC converter with PFC for charging of electric vehicles. IEEE Trans. Transp. Electrif. 2017, 3, 536-544. [CrossRef]

12. Wang, H.; Shang, M.; Khaligh, A. A PSFB-based integrated PEV onboard charger with extended ZVS range and zero duty cycle loss. IEEE Trans. Ind. Appl. 2017, 53, 585-595. [CrossRef]

13. Albiol-Tendillo, L.; Vidal-Idiarte, E.; Maixe-Altes, J.; Mendez-Prince, S.; Martinez-Salamero, L. Seamless sliding-mode control for bidirectional boost converter with output filter for electric vehicles applications. IET Power Electron. 2015, 8, 1808-1816. [CrossRef]

14. Kim, S.; Kang, F.S. Multifunctional onboard battery charger for plug-in electric vehicles. IEEE Trans. Ind. Electron. 2015, 62, 3460-3472.

15. Zahid, Z.U.; Dalala, Z.M.; Chen, R.; Chen, B.; Lai, J.S. Design of bidirectional DC-DC resonant converter for vehicle-to-grid (V2G) applications. IEEE Trans. Transp. Electrif. 2015, 1, 232-244. [CrossRef]

16. Hua, C.C.; Fang, Y.H.; Lin, C.W. LLC resonant converter for electric vehicle battery chargers. IET Power Electron. 2016, 9, 2369-2376. [CrossRef]

17. Yilmaz, M.; Krein, P.T. Review of battery charger topologies, charging power levels, and infrastructure for plug-in electric and hybrid vehicles. IEEE Trans. Power Electron. 2013, 28, 2151-2169. [CrossRef]

18. Sfakianakis, G.E.; Everts, J.; Lomonova, E.A. Overview of the requirements and implementations of bidirectional isolated AC-DC converters for automotive battery charging applications. In Proceedings of the 2015 Tenth International Conference on Ecological Vehicles and Renewable Energies (EVER), Monte Carlo, Monac, 31 March-2 April 2015; IEEE: Piscataway, NJ, USA, 2015; pp. 1-12.

19. Bertoluzzo, M.; Zabihi, N.; Buja, G. Overview on battery chargers for plug-in electric vehicles. In Proceedings of the 2012 15th International Power Electronics and Motion Control Conference (EPE/PEMC), Novi Sad, Serbia, 4-6 September 2012; IEEE: Piscataway, NJ, USA, 2012; p. LS4d-1.

20. Chang, H.C.; Liaw, C.M. An integrated driving/charging switched reluctance motor drive using three-phase power module. IEEE Trans. Ind. Electron. 2010, 58, 1763-1775. [CrossRef]

21. Shi, C.; Tang, Y.; Khaligh, A. A three-phase integrated onboard charger for plug-in electric vehicles. IEEE Trans. Power Electron. 2017, 33, 4716-4725. [CrossRef]

22. Shi, C.; Khaligh, A. A two-stage three-phase integrated charger for electric vehicles with dual cascaded control strategy. IEEE J. Emerg. Sel. Top. Power Electron. 2018, 6, 898-909. [CrossRef]

23. Emadi, A.; Lee, Y.J.; Rajashekara, K. Power electronics and motor drives in electric, hybrid electric, and plug-in hybrid electric vehicles. IEEE Trans. Ind. Electron. 2008, 55, 2237-2245. [CrossRef]

24. Lukic, S.M.; Cao, J.; Bansal, R.C.; Rodriguez, F.; Emadi, A. Energy storage systems for automotive applications. IEEE Trans. Ind. Electron. 2008, 55, 2258-2267. [CrossRef]

25. Khaligh, A.; Dusmez, S. Comprehensive topological analysis of conductive and inductive charging solutions for plug-in electric vehicles. IEEE Trans. Veh. Technol. 2012, 61, 3475-3489. [CrossRef]

26. Shen, J.; Dusmez, S.; Khaligh, A. Optimization of sizing and battery cycle life in battery/ultracapacitor hybrid energy storage systems for electric vehicle applications. IEEE Trans. Ind. Inform. 2014, 10, 2112-2121. [CrossRef]

27. Sabzehgar, R.; Roshan, Y.M.; Fajri, P. Modelling and sliding-mode control of a single-phase single-stage converter with application to plug-in electric vehicles. IET Power Electron. 2019, 12, 620-626. [CrossRef]

28. Onar, O.C.; Kobayashi, J.; Erb, D.C.; Khaligh, A. A bidirectional high-power-quality grid interface with a novel bidirectional noninverted buck-boost converter for PHEVs. IEEE Trans. Veh. Technol. 2012, 61, 2018-2032. [CrossRef]

29. Amjadi, Z.; Williamson, S.S. Digital control of a bidirectional DC/DC switched capacitor converter for hybrid electric vehicle energy storage system applications. IEEE Trans. Smart Grid 2014, 5, 158-166. [CrossRef]

30. Kisacikoglu, M.C.; Kesler, M.; Tolbert, L.M. Single-phase on-board bidirectional PEV charger for V2G reactive power operation. IEEE Trans. Smart Grid 2015, 6, 767-775. [CrossRef] 
31. Khan, M.A.; Ahmed, A.; Husain, I.; Sozer, Y.; Badawy, M. Performance analysis of bidirectional DC-DC converters for electric vehicles. IEEE Trans. Ind. Appl. 2015, 51, 3442-3452. [CrossRef]

32. Shang, Y.; Liu, K.; Cui, N.; Zhang, Q.; Zhang, C. A sine-wave heating circuit for automotive battery self-heating at subzero temperatures. IEEE Trans. Ind. Inform. 2019. [CrossRef]

33. Shang, Y.; Liu, K.; Cui, N.; Wang, N.; Li, K.; Zhang, C. A Compact Resonant Switched-Capacitor Heater for Lithium-Ion Battery Self-Heating at Low Temperatures. IEEE Trans. Power Electron. 2019. [CrossRef]

34. Liu, S.; Xie, X.; Yang, L. Analysis, Modeling and Implementation of a Switching Bi-Directional Buck-Boost Converter Based on Electric Vehicle Hybrid Energy Storage for V2G System. IEEE Access 2020, 8, 65868-65879. [CrossRef]

35. Veerachary, M. Analysis of minimum-phase fourth-order buck DC-DC converter. IEEE Trans. Ind. Electron. 2015, 63, 144-154. [CrossRef]

36. Ouyang, Q.; Wang, Z.; Liu, K.; Xu, G.; Li, Y. Optimal Charging Control for Lithium-Ion Battery Packs: A Distributed Average Tracking Approach. IEEE Trans. Ind. Inform. 2019. [CrossRef]

37. Liu, K.; Li, K.; Zhang, C. Constrained generalized predictive control of battery charging process based on a coupled thermoelectric model. J. Power Sources 2017, 347, 145-158. [CrossRef]

38. Shtessel, Y.; Baev, S.; Biglari, H. Unity power factor control in three-phase AC/DC boost converter using sliding modes. IEEE Trans. Ind. Electron. 2008, 55, 3874-3882. [CrossRef]

39. Roshan, Y.M.; Maravandi, A.; Moallem, M. Power electronics control of an energy regenerative mechatronic damper. IEEE Trans. Ind. Electron. 2015, 62, 3052-3060. [CrossRef]

(C) 2020 by the authors. Licensee MDPI, Basel, Switzerland. This article is an open access article distributed under the terms and conditions of the Creative Commons Attribution (CC BY) license (http:/ / creativecommons.org/licenses/by/4.0/). 